\title{
Sürdürülebilir Ulaşım İçin Güneş Enerjili Teknelerin Kullanılması ve Çevresel Etkileri
}

\author{
Şafak HENGIRMEN TERCAN ${ }^{*}$ \\ ${ }^{1}$ İnşaat Mühendisliği Bölümü, Mühendislik Fakültesi, Hasan Kalyoncu Üniversitesi, Gaziantep, Türkiye \\ *1s safak.tercan@hku.edu.tr
}

(Geliş/Received: 25/08/2020;

Kabul/Accepted: 21/10/2020)

\begin{abstract}
Öz: Sürdürülebilir ulaşım, taşımacıllğın çevresel olumsuz etkilerinin azaltılması ve yenilenebilir enerjilerin kullanılması için yenilikçi bir sektördür. Güneş enerjisi ise sadece elektrik üretimi için değil aynı zamanda ulaşım sektörü için de alternatif bir enerji kaynağıdır. Bu çalışmada, baraj gölleri, içme suyu kaynakları ve hassas ekosistemler gibi doğal güzellikleri bulunan alanlarda oluşan turistik bölgelerde, sürdürülebilir ulaşım türü olan güneş enerjili teknelerin kullanılması ve çevresel etkileri araştırılmıştır. Araştırmada, Türkiye'de ilk kez uygulaması yapılan ve iç hizmetleri için gerekli elektrik ihtiyacını güneş enerjisinden sağlayan bir tur teknesinin çevresel etkileri 2 şekilde incelenmiştir. İlk değerlendirme güneş enerjisi sisteminin simülasyon sonuçlarına göre yapılmıştır. Daha sonra tekne 1 yıllık işletme süresi sonuçlarına göre tekrar değerlendirilmiş ve \% 16 yakıt tasarrufu gerçekleştiği hesaplanmıştır. Gerçekleşen sonuçlara göre 1 tekne için yıllık yaklaşık 4 ton $\mathrm{CO}_{2}$ emisyon azaltımı sağlanmıştır. Sonuçlar, sürdürülebilir ulaşım konusundaki çalışmalara örnek oluşturacak ve hassas ekosistemlerdeki ulaşımın çevresel etkilerini azaltarak bu bölgelerin sürdürülebilirliğini artıracaktır.
\end{abstract}

Anahtar kelimeler: Sürdürülebilir ulaşım, güneş enerjili tekne, iklim değişikliği, emisyon azaltımı.

\section{Solar Boats for Sustainable Transportation and Their Environmental Impacts}

\begin{abstract}
Sustainable transport is an innovative sector to reduce the negative environmental effects of transport and to use renewable energies. Solar energy is an alternative energy source not only for energy production but also for the transportation sector. This study, researched a solar powered boat for sustainable transportation in the touristic areas, such as dam lakes, drinking water sources and sensitive ecosystems. A touristic boat is equipped with photovoltaic panels for all internal services required in the touristic boats and aimed to decrease the environmental impacts. The environmental impacts are evaluated in two ways. The first evaluation was made according to the simulation results of the solar energy system before the installation of photovoltaic panels. Secondly, the boat was re-evaluated according to the 1-year operating period results after the photovoltaic panels installed and a $16 \%$ fuel saving was calculated. Approximately, 4 tons of $\mathrm{CO}_{2}$ emission reduction is achieved for 1 boat according to the 1-year operating period results. The results will support the studies on sustainable transport and increase the sustainability of the regions by reducing the environmental impacts of transport in sensitive ecosystems.
\end{abstract}

Key words: Sustainable transport, solar boat, climate change, emission reduction.

\section{Giriş}

İklim değişikliği 21. yüzyıl için dünyanın en önemli sorunlarından birisidir ve kentsel sürdürülebilirlik konusu insanlık için kritik bir başlıktır [1]. İklim değişikliği sorunu, su kuraklıkları, yüksek sıcaklıklar, yüksek yağmur yoğunlukları veya yüksek rüzgâr rejimleri gibi çeşitli şekillerde ortaya çıkmaktadır. Özellikle adalar, kıyılar, nehir havzaları, baraj gölleri, içme suyu kaynakları ve sulak alanlar gibi hassas ekosistemler korunması gereken bölgelerdir. Uzmanlar hassas ekosistemlerde görülen iklim değişikliği etkilerini azaltmak amacıyla birçok azaltım ve uyum faaliyetleri yapmaktadır. Bu bölgeler, doğal güzellikleri ve içlerinde barındırdıkları canlı türleri ile çeşitli turistik faaliyetler için de cazip yerlerdir. Turizmin canlandığı bu bölgeler, teknelerle ve gemilerle gezinti, durgun su sporları adıyla anılan kano, kürek, su bisikleti ve yelken spor dalları gibi çok sayıda turistik aktiviteye de sahiptir.

Türkiye'de 2020 yılı itibari ile 76 adet tescilli sulak alan ve 504 baraj bulunmaktadır [2]. Baraj göllerinde elektrik üretimi ve sulama faaliyetlerinin yanı sıra turizm, balıkçılık veya kuş gözlemleri gibi çeşitli ticari ve bilimsel faaliyetler de yapılmaktadır. Uygun olan baraj göllerinde, turistlerin teknelerle gezinti yapmaları bölgede yaşayan halk için önemli bir iş imkânı yaratmaktadır. Baraj gölleri, aynı zamanda içme suyu kaynağı olarak da kullanılmaktadır. Bu sebeple, baraj göllerinde kullanılan ulaşım türlerinin çevresel zararlarının çok düşük veya temiz teknolojiler kullanan sürdürülebilir ulaşım türleri olması gerekmektedir. Elektrikli tekneler veya güneş

\footnotetext{
Sorumlu yazar: safak.tercan@ @ku.edu.tr. Yazarın ORCID Numarası: ${ }^{1}$ 0000-0002-1729-6421
} 
enerjisi ile çalışan tekneler bu konuda çözüm sunmaktadır. Ancak, Türkiye'de hassas ekosistemlerde böyle bir ulaşım türü için daha önce yapılmış herhangi bir çalışma bulunmamaktadır.

Bu çalı̧̧mada, Fırat Nehri üzerindeki Birecik Baraj gölünün oluşmasıyla turistik bir bölge haline gelen Gaziantep-Rumkale ve Halfeti'de sürdürülebilir ulaşım için turistik tur teknelerinde güneş enerjisi kullanılması araştırılmıştır. Birecik Baraj Gölünde bir pilot proje uygulaması olarak yapılan ve iç hizmetleri için gerekli elektrik ihtiyacını güneş enerjisinden sağlayan bir teknenin çevresel etkileri simülasyon sonuçlarına ve 1 yıllık işletim verilerine göre ayrı ayrı incelenmiştir. Çalışmanın sonuçları, Birecik Baraj Gölünde sürdürülebilir ulaşım ve sürdürülebilir turizme katkı sağlarken içme suyu kaynağı olan baraj gölünün kirlenmesini önleyecek çözümler sunmaktadır.

\subsection{Literatür araştırması}

$35.000 \mathrm{~km}$ sahil şeridi olan Avustralya, korunması gereken hassas ekosistemler için iyi bir örnektir. Ülkede deniz turizmi yapılan cazibe merkezlerinde oluşan sera gazı emisyonları yıllık 70.000 ton $\mathrm{CO} 2$ eşdeğeridir. $\mathrm{Bu}$ miktar aynı zamanda Avustralya'da sera gazı üretimi açısından en hızlı büyüyen sektör olan ulaştırma sektörünün \%1'ini oluşturmaktadır. Avustralyalı tur teknesi işletmecileri ile ilgili bir çalıșmaya göre; bir turistin karbon ayak izi, dizel motorlu bir tekne turuna katıldığ takdirde turist başına $61 \mathrm{~kg} \mathrm{CO}$, benzin motorlu bir tekne turuna katıldığı takdirde ise turist başına $27 \mathrm{~kg} \mathrm{CO}$. eşdeğeridir. Bu emisyon değerleri, standart bir binek aracında $300 \mathrm{~km}$ veya $140 \mathrm{~km}$ sürüş yapan tek bir kişinin oluşturduğu emisyon değerine eşittir [3].

Benzer şekilde dünyadaki diğer adalar, turizmin olumsuz etkileri ile karşı karşıyadır. Özellikle Akdeniz ve Karayip bölgelerindeki çok sayıda ada, kitle turizmi ile özdeşleşmiştir. Adaların coğrafi, kültürel, ekolojik ve ekonomik özellikleri ziyaretçileri çekerken, bu unsurların kırılganlı̆̆ı ve sinırlamaları ada ortamını ve topluluklarını turizm baskılarına karşı daha savunmasız hale getirmektedir [4]. Yenilenebilir enerji kaynakları bu problemler için iyi bir çözüm olabilmektedir. Turizm açısından cazibe merkezi olan bazı bölgelerde çeşitli projeler uygulanmıştır. Örneğin; Tayland'daki Koh Jik adasında elektrik ihtiyacını karşılamak için teknolojik ve ekonomik bilgiler sağlamak üzere bir dizi mikro-grid senaryosu modellenmiş ve değerlendirilmiştir. Uygulanan projelerde, fotovoltaik (PV) paneller ile elektrik üretilmiş ve 2 çeşit akü bu elektrikle şarj edilmiştir. Sonuçlara göre, en düşük elektrik maliyeti Li-ion aküler kullanıldığında $0.220 € / \mathrm{kWs}$ olarak elde edilmiş, en düșük proje geri ödeme süresi de kurşun asit aküler kullanıldığında $0.307 € / \mathrm{kWs}$ ve 6,3 yıl olarak oluşmuştur [5]. Maldivler'de bir başka mikrogrid projesi hayata geçirilmiştir. Rüzgâr ve güneş sistemlerini kullanarak hibrit bir tasarım yapılmıştır. Kullanıcılardan, taleplerini gerektiği zaman ayarlayarak gönüllü olarak tüketim yüklerini azaltmaları istenmiştir [6].

Avrupa Ülkelerinin iddialı hedefleri ile dünyadaki yenilenebilir enerji sektörü büyümektedir. Çoğu ülke 2015 yılında Paris Anlaşması'nı imzalamış ve sera gazı emisyonlarını azaltmak için kendi hedeflerini belirlemiştir. Bazıları önümüzdeki yıllarda \%100 yenilenebilir enerji kullanımına ulaşmayı planlamaktadırlar. 2050 Danimarka enerji sistemi için \%100 yenilenebilir enerji senaryosunu kullanan bir çalışma, mevcut elektrik piyasası yapısının bu hedefe geçiş için gerekli rüzgâr enerjisi miktarlarını finansal olarak sürdüremediği sonucuna varmıştır. Danimarka'nın hedeflerinin gerçekleştirilmesi için elektrik ticaretinin kurumsal yapısının yeniden şekillendirilmesi gerekmektedir [7]. Diğer yandan, Akdeniz havzasında bulunan Türkiye, büyük bir yenilenebilir enerji potansiyeline ve bunu kullanmak için birçok teşvike sahiptir. Ülkenin gerçekleștirilebilir yenilenebilir enerji potansiyeli, AB-27'nin toplam yenilenebilir enerji potansiyelinin \%13'üne eşittir. Türkiye'nin güneş potansiyelinin yaklaşık $\% 0,45$ 'i kullanılabilir hale getirilmiştir. Son yıllarda da, güneş ve rüzgâr enerjisi gibi teknolojiler enerji üretiminde etkili olmaya başlamıştır [8].

Güneş enerjisi sadece enerji üretimi için değil aynı zamanda ulaşım sektörü için de çok etkilidir. Sürdürülebilir ulaşım, taşımacılığın çevresel olumsuz etkilerinin azaltılması ve yenilenebilir enerjilerin kullanılması için yenilikçi bir sektördür. Sürdürülebilir ulaşım hakkında 2000-2019 yılları arasında yayınlanan makalelerin derlendiği bir çalıșmanın analiz sonuçlarına göre, "araçlar için yeni yakıtlar" konusu derleme makalesinde belirtilen 9 önemli araştırma konusundan biridir [9]. Aynı zamanda, araştırmacılar, yeni bir yakıt alternatifi ve iklim değişikliğinin hafifletilmesi için güneş enerjili tekneleri üzerinde çalışmaktadır. Tanzanya'da yapılan bir araştırmada, balıkları ağlarına çekmek için gazyağı fenerleri kullanan balıkçılara alternatif bir enerji kullanmaları önerilmiştir. Bu alternatifte, balıkçılar akülerle çalışan LED aydınlatma sistemini kullanmışlar ve 34 ay geri ödeme süresi ile yatıımlarını geri döndürmüşlerdir. Bu sayede, aydınlatma ekipmanı ve yakıta harcadıkları kazançlarının \%35 ila \%50'sini tasarruf etmişlerdir [10].

Dünya çapında elektrikli tekneler giderek daha da ilgi çekici olmaya başlamış ve elektrikli arabalarla benzer şekilde kendilerini mevcut pazarı geliştiren teknoloji olarak konumlandırmışlardır. Günümüzde, nakliye gemileri ve savaş gemileri dâhil modern gemilerde, elektrikli tahrik sistemleri yaygın olarak kullanılmaktadır. 
Araştırmacılar, yalnızca tahrik sistemini değil, aynı zamanda navigasyon ve gemi hizmetleri gibi diğer tüm hayati işlevleri de içeren tamamen elektrikli gemiler üzerinde çalışmaktadırlar [11]. Teknelerdeki fotovoltaik paneller yenilikçi ve etkin bir çözüm olarak çalışılmaktadır. Avrupa'da güneş enerjisi ile çalışan tekne örnekleri piyasada kullanılmaktadır (Şekil 1). Avusturyalı bir şirket güneş enerjili birkaç model tekneyi piyasaya sürmüştür. Maksimum 3-4 kişilik olan bir modelde $800 \mathrm{~W}$ bir güverte üstü motor ve $5 \mathrm{kWs}$ bir kurşun asit akü bulunmaktadır. $\mathrm{Bu}$ teknedeki güneş panelleri yaklaşık olarak $4 \mathrm{~m}^{2}$ kaplamakta, $0,4 \mathrm{kWp}$ bir pik kapasitesi bulunmakta ve yaz döneminde günlük olarak 1,6 kWs elektrik üretmektedir. Bu tekne 6,5 saat tam güçte 4,7 knot sürüş hızı ile çalışabilmekte ve 3 günde şarj edilmektedir. Dolayısıyla, bu tekne hafta sonu kullanımı için uygundur [12].

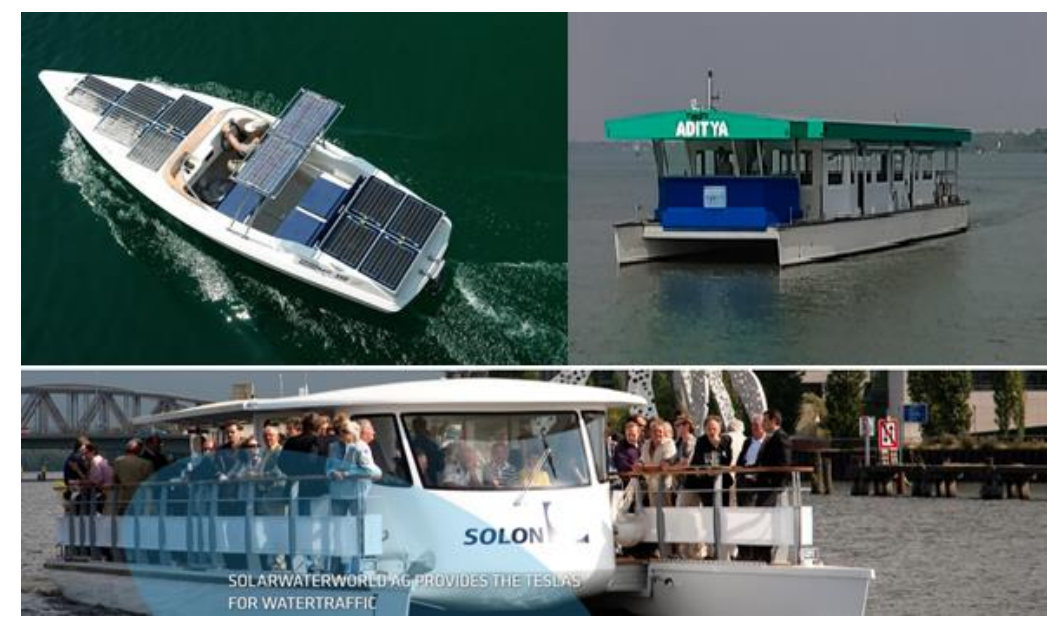

Şekil 1. Avrupa'da kullanılan güneş enerjili tekne örnekleri.

Diğer bir model, güneş enerjili tekne-taksidir. Bu taksi bir iskeleden diğerine 7 kişiye kadar insan taşıyabilecek şekilde tasarlanmıştır. $4,4 \mathrm{~kW}$ bir motora ve yaklaşık $1 \mathrm{kWp}$ güneş ve 17,5 kWs kurşun asit akü kapasitesine sahiptir. Akü sistemini şarj etmesi yaklaşık olarak 5 gün aldığ 1 için bu taksinin kullanımı da sınırlıdır. Katamaran tipi bir başka tekne, iki adet $8 \mathrm{~kW}$ elektrik motora ve maksimum 46 yolcu kapasitesine sahiptir. Teknenin çatısına monte edilmiş toplam $6 \mathrm{kWp}$ 'lik fotovoltaik panellere ve 5 knot hıza sahip olan bu 20 tonluk tekne, omurgasına saklanmış olan 46 kWs'lik akü sistemi ile 8 saate kadar çalışabilmektedir [13].

Daha büyük yolcu feribotları da elektrikli motor, lityum iyon akü takımı ve entegre fotovoltaik modüller tarafından beslenen güneş enerjili örnekler sunmaktadır. Hindistan'da üretilen, 75 yolcu kapasiteli, güneş enerjili bir feribot iki adet $20 \mathrm{~kW}$ asenkron elektrik motora sahiptir. Teknenin çatısındaki $20 \mathrm{kWp}$ polikristalin fotovoltaik paneller ve maksimum 7,5 knot seyir hızı ile 20 m uzunluğundaki ve 7 m genişliğindeki tekne güneşli günlerde 6 saate kadar ve bulutlu günlerde 4,5 saate kadar çalışabilmektedir. Akü takımı 2 adet 25 kWs Lityum demir fosfat aküden oluşmaktadır [14].

\subsection{Teknelerin çevresel etki analizi}

Deniz ulaşımı, yanan yakıt atıklarının salınması ve ses emisyonu yolu ile deniz ekosistemlerinin kirletilmesinin en önemli 3'üncü kirlilik kaynağıdır [15]. Deniz kirliliğinin \%12'si deniz temelli faaliyetlere yani deniz ulaşımı, hidrokarbonların ve tehlikeli maddelerin nakliyesi, liman faaliyetleri, tekne/liman ara yüzü, petrol sızıntısı gibi kazalar, gaz arıtımı, diğer salınımlar ve eğlence için deniz yolculuğuna atfedilebilir [16]. Güneş enerjisinin kullanımı deniz, baraj ve hassas ekosistemlerde kirliliğin önlenmesi bakımından önemli bir çözümdür. Türkiye'de 2010 tarihli “İç Sularda Çalışan Gemi ve İç Su Araçları Yönetmeliği” Madde 8-(1)'e göre; içme ve kullanma suyu temin edilen iç sularda akaryakıt ile çalışan kayık, motor ve benzeri araçların kullanılmasına izin verilmez ancak bazı mecburi durumlarda belirli şartlara bağlı olarak Devlet Su İşleri Genel Müdürlüğünce izin verilebilmektedir. [17] Avrupa Birliği Yönergesi 92/75/EEC [18], tekne teçhizatlarının da içerisine girdiği bir enerji tüketimi etiketleme şeması oluşturmuştur. Rumkale-Halfeti teknelerinin çevresel etkilerini değerlendirmek için hava kalitesi, su kalitesi ve gürültü kirliliği göz önüne alınacaktır: 


\subsubsection{Hava kalitesi}

CO gazı, benzin veya propan gibi yakıtlar yandığında üretilen ölümcül bir zehirdir. Motor egzozunda bulunan ve tamamlanmamış yanmanın neden olduğu birçok kimyasaldan birisidir. CO renksiz, kokusuz ve tatsız bir gaz olduğundan dolayı, maruz kalan insanı hiçbir uyarı olmaksızın alt edebilir. İlk semptomlar arasında baş ağrısı, baş dönmesi, sersemleme ve mide bulantısı yer alabilir. Uzun süreli ya da yüksek maruziyetlerle karşılaşılması durumunda, semptomlar kusma, bilinç kaybı ve bayılma olarak ilerler [19].

Amerika'da Sağlık ve İnsan Hizmetleri Biriminin 2003'te yayınladığı "Çeşitli İşletim Koşulları Altındaki Gezinti Teknelerinde Karbon monoksit emisyonu ve maruziyeti” [20] isimli araştırma, tehlikeli CO gazının konsantrasyonlarının birçok gezinti teknesi modelleri ve markalarında meydana geldiğini göstermektedir. Bu problem hem eski hem de yeni tekneler ve motorlarda oluşmaktadır. Üç farklı yöntem ile ölçülmüş olan CO konsantrasyonları, birçok tekne için 1.200 ppm eşiğine yaklaşıldığını veya bunun geçildiğini göstermiştir [20]. Bu yüksek CO maruziyetleri insan sağlı̆̆ına kötü etki etmektedir. Güneş enerjili tekne konseptine geçiş hava kalitesi üzerinde büyük bir pozitif etkiye sahip olacaktır. Elektrikli bir motorun güneş enerjili PV sistemi ile çalışan bir motora dönüştürülmesi bütün temel fosil yakıt tüketiminin yerini alacak ve fosil yakıtlarından kaynaklanan bütün emisyonları ortadan kaldıracaktır.

\subsubsection{Su kalitesi}

Suyun kalitesi tekne motorları da dâhil olmak üzere birçok kaynak yolu ile suya doğrudan eklenebilecek olan metaller (kurşun, kadmiyum, cıva), besin maddeleri (fosfor, nitratlar) ve hidrokarbonlar (metan, benzin, petrol temelli ürünler) tarafından negatif yönde etkilenmektedir [21]. Besin maddeleri göllerde ve nehirlerde yosun büyümesine etki edebilir ve çözünmüş oksijen ve $\mathrm{pH}$ seviyeleri biyo-çeşitliliğin türünü ve çokluğunu etkilerken, su berraklığı üzerinde bir etkiye sahip olabilir. Buna ek olarak, bu maddeler su kaynağının aynı zamanda içme suyu kaynağı olarak kullanıldığı durumlarda insan sağlığı üzerinde de etkilere sahip olabilir [21]. Tekne motorları büyük miktarda güç sağlamak için tasarlanmışlardır. Bu nedenle, yolculuk sırasında bir miktar yakıt yanmadan suya karışmaktadır. Suya ne kadar yakıtın geçeceği konusunda tahminler çeşitlilik göstermekte ve motor hızı, ayar, yakıt karışımı ve güç gibi faktörlere dayanmaktadır. Ancak, tüm dıştan takma motorlarda yaklaşık \%25 ila \%30 kadar yakıtın yanmadan doğrudan suya karışması makul bir ortalama olarak kabul edilmektedir [21]. Bu sebeple, Avrupa'daki birçok ülkedeki tatlı su göllerinde iki zamanlı dıştan takma motorların kullanımı yasaklanmıştır [22]. Teknelerde, yanmamış veya tam olarak yanmamış yakıt, petrol partikülleri veya kalıntıları çevreye salınmaktadır. Kirlilik yaratan maddelerin miktarı az olsa da, belirli bölgelerde birikerek özellikle de tekneler bağlı dururken etraftaki su üzerinde petrol filmine neden olmaktadır. Güneş enerjili tekne konseptine geçiş Halfeti'nin su kalitesi üzerinde çok büyük bir pozitif etkiye sahip olacaktır. Elektrikli bir motorun güneş enerjili PV sistemine dönüştürülmesi bütün temel yakıt tüketimini değiştirir.

\subsubsection{Gürültü kirliliği}

Teknelerden kaynaklanan gürültü, deniz memelileri, balıklar ve kuşlar da dahil olmak üzere, deniz hayvanlarında rahatsızlığa neden olmaktadır [23]. Turist teknelerinin ses etkisi insanlar ve gezinti deneyimi üzerinde negatif bir etkiye sahiptir. Teknelerden gelen sesin temel kaynağı motor tarafından üretilir ve atmosfer yolu ile dağılabilir veya aracın gövdesi yolu ile aktarılabilir. Havaya ya da suya aktarılan sesin hacmi motorun boyutuna, tasarımına ve konumuna ve aracın büyüklüğüne ve inşa edilişs şekline göre değişecektir. Bu gürültü aralığı, 10 m uzaktaki bir dizel kamyon ile rahatsızlık eşiği arasında yani 90-120 dB (desibel) seviyelerinde olabilmektedir [24]. Güneş enerjili tekne konseptine geçiş ses emisyonu üzerinde büyük bir pozitif etkiye sahip olacaktır. Bir elektrikli motorun transferi özellikle yanmış egzoz gazlarının ortadan kaldırılması dolayısıyla ve motorun hareketli kısımlarının azaltılması ile ses seviyelerini önemli ölçüde azaltacaktır. Ses seviyesinin azaltılması ve ortadan kaldırılması turistlerin de yolculuk deneyimlerini pozitif yönde etkileyecektir.

\section{Materyal ve Yöntem}

\subsection{Simülasyon ve tekne özellikleri}

Çalışmada PV*SOL [25] simülasyon programı kullanılarak Rumkale-Halfeti bölgesinin güneş enerjisi potansiyeli belirlenmiştir. $\mathrm{PV} * \mathrm{SOL}$ simülasyon programı güneş enerjisi sistemleri tasarlarken, sistemin 
büyüklüğü ve yönü, elektrikli cihazların sayısı ve kullanım süresi, sistemin bulunduğu bölgenin genel iklim koşulları ve güneş radyasyonu, yerel şebeke dağıtımı gibi çok sayıda faktörü hesaba katmaktadır. Simülasyon programı ile sistem kapasitesi, yıllık güç üretimi ve performansı hesaplanarak gerekli olan batarya sistemi ve invertör gücü belirlenmiştir.

Çalışmada kullanılacak olan tekne bölgede çalışan turistik tur teknelerinden en yaygın tasarımlardan birisi olarak seçilmiştir. 25 tonluk ve 45 yolcu kapasiteli bir teknedir. Teknenin mevcut teknik durumu yerinde yapılan gözlemlerle elde edilmiştir. Tekne üzerine kurulması planlanan panel ağırlıklarının teknenin dengesinin bozulması ile ilgili hesaplar ve daha verimli tekne tasarımları hazırlanması bu çalışmada incelenmemiştir. Güneş panelleri teknenin üst güvertesine gölgelik şeklinde monte edilmiş ve iç servis hizmetlerinde kullanılacak elektriği güneşten üretecek şekilde tasarlanmıştır. Çalışmada iki şekilde emisyon azaltım hesaplaması yapılmıştır. İlk olarak, montajı yapılan güneş panellerinden elde edilmesi planlanan enerji hesapları ile tahmini bir emisyon azaltımı hesaplanmıştır. Daha sonra tekne 1 yıl boyunca işletilmiş ve gerçekleşen dizel yakıt kullanımına göre karbon emisyonları hesaplanmıştır. Her iki hesaplamada IPCC'nin (Intergovermental Panel on Climate Change) 2006 Kılavuzu Yöntemi kullanılmıştır [26].

\section{2. Çalıșma alanı}

Gaziantep, Türkiye'deki en hızlı büyüyen şehirlerden ve en dinamik kentsel ekonomilerden birisidir. Gaziantep'in nüfusu 2020 yılı itibari ile yaklaşık 2,1 milyondur [27]. Gaziantep, genç nüfusu, büyük dinamik ekonomik yapısı, gastronomi turizmi ve diğer turizm potansiyeli ile bir cazibe merkezidir. Yüzölçümünün 1/4’ü Firat Nehri'nden yararlanan verimli tarımsal topraklardır.

Yenilenebilir Enerji Genel Müdürlüğü tarafından hazırlanmış olan ve Şekil 2'de gösterilen Türkiye'nin Güneş Enerjisi Haritasına [28] göre Gaziantep ve çevresinde, toplam yıllık 1şınım zamanı 2.698,5 saatin üzerinde (toplamda günlük 7,5 saat) [29] ve elde edilen toplam güneş enerjisi her yıl $1.500 \mathrm{kWs} / \mathrm{m} 2$ 'den veya günlük 4,2 $\mathrm{kWs} / \mathrm{m} 2$ 'den fazladır.

Rumkale-Halfeti, Fırat nehrinin batı ve doğu kıyısında yer alan alanlardır. Halfeti küçük bir tarım kasabasıdır ve Gaziantep'e yaklaşık 100 km'dir. Kasabanın büyük kısmı 1990'larda Fırat Nehri üzerinde yer alan Birecik Barajının suları altında kalmıştır. Bölge bu nedenle tarım alanlarını kaybetmiş ancak baraj gölü ile görsel olarak çok güzel bir kanyona dönüşmüştür. $\mathrm{Bu}$ muhteşem kanyon kısa sürede turistlerin ilgisini çekmiş ve bölge Rumkale-Zeugma-Halfeti olarak turistik bir merkez olmuştur. Aynı zamanda sular altında kalmış olan Eski Halfeti kasabasının yapıları sualtı turizmi potansiyelini de barındırmaktadır. Halfeti'den Rumkale'ye turizm amaçlı dizel tur tekneleri çalışmaktadır. Bu tekneler, Rumkale'nin bulunduğu sarp kayalıkların arasından 20 dakika süren bir gezi turu düzenlemektedirler. Rumkale'de, hepsi iyi şekilde korunmuş olan bir cami, kilise ve manastır görülmektedir. Tekneler, sular altında kalmış olan başka bir kasaba olan Savaş’a kadar 10 dakika daha ilerler ve yaklaşık olarak 40 dakika sonra kendi limanı olan Halfeti'ye geri döner. Halfeti'de halen hizmet veren yaklaşık 40 turistik tekne vardır. Turistlerin sayısına ve seyahat taleplerine dayalı olarak tekneler günde 5 defa veya yılda yaklaşık 500 sefer yapmaktadırlar.

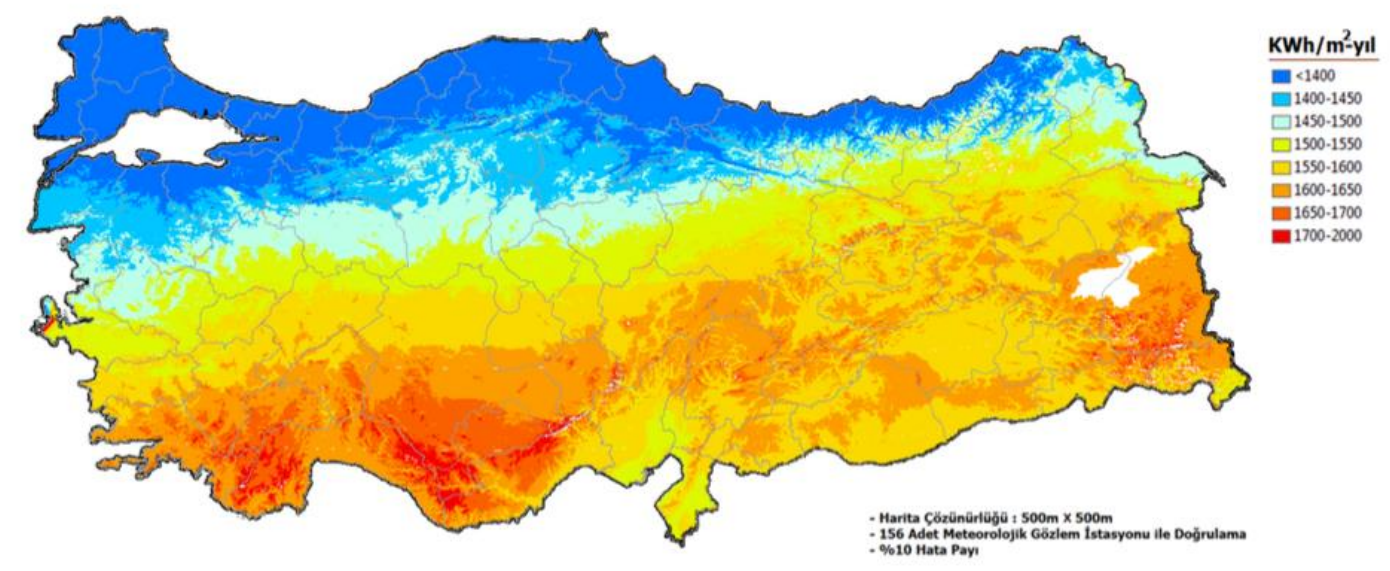

Şekil 2. Türkiye'nin ışınım haritası [28]. 


\section{Sonuçlar}

Bölge, Gaziantep'e yakın olarak güneş enerjisi potansiyeli açısından çok avantajlı bir konuma sahip olduğu için yıllık ortalama gün 1şığı süresi 2978 saat ve toplam güneş enerjisi potansiyeli $1586 \mathrm{kWs} / \mathrm{m} 2$ 'dir [28]. Gaziantep'in potansiyeli hakkındaki kabaca tahminlere göre 100 kWp'lik bir PV montajı yaklaşı olarak 166,100 kWs güneş enerjisi elektriği üretebilmektedir [28]. Kurulan sistemin kriterleri simülasyon programında, sabit sistem, \%14 sistem kaybı, \%96 inverter verimliliği ve doğru akımdan alternatif akıma dönüştürülme katsayısı 1,2 olarak alınmıştır. Kurulan sistem teknenin üst güvertesine aynı zamanda gölgelik olacak şekilde monte edilmiştir. Üst güverte $25 \mathrm{~m} 2$ alana sahiptir ve 15 adet 1641x990x40 ölçülerindeki PV paneli Şekil 3'de görüldüğü gibi yerleştirilmiştir. Modüllerin ürün etkinliği \%16.63'dür. Sistemdeki inverter $4400 \mathrm{~W}$ kapasiteye sahiptir ve 12 Voltluk ve 200 Ah'llk dört akü tekneye entegre edilmiş̧ir. Kurulan sistem tur teknesinin iç hizmetlerini karşılayacak şekilde enerji üretecektir. Teknedeki iç hizmet enerji ihtiyacı ve beklenen tüketim şöyledir; • Aküler, 4,8 kWs $\bullet$ Televizyon, $400 \mathrm{~W} \bullet$ Navigasyon sistemi, $50 \mathrm{~W} \bullet$ Dizüstü bilgisayar, $50 \mathrm{~W} \bullet$ Aydınlatma sistemi, 150 $\mathrm{W} \bullet$ Ses sistemi, $300 \mathrm{~W} \bullet$ Pompalar, $500 \mathrm{~W} \bullet$ Buzdolabı, 400W ve • Çay-kahve makinası, $1000 \mathrm{~kW}$ olarak belirlenmiş̧ir. Teknenin motoru dizel motor olarak bırakılmış ve güneş panelleri tekne seyahat ederken veya hareket halinde değilken teknedeki iç hizmetler için gerekli olan elektriği karşllayacak şekilde tasarlanmıştır. Teknedeki PV paneller 24V ve 200 Ah 2 adet akü bataryasını şarj etmekte ve bir inverter aracilığıyla teknedeki $220 \mathrm{~V}$ hat üzerindeki yukarıda belirtilen iç hizmet yüklerini beslemektedir. Teknede jeneratör bulunmamaktadır. Aynı zamanda, Birecik Baraj Gölünde seyreden diğer teknelerin acil durum ihtiyaçlarında tekne kurtarma faaliyetlerine akülerle pompa desteği vererek yardımcı olacağı düşünülmüştür.

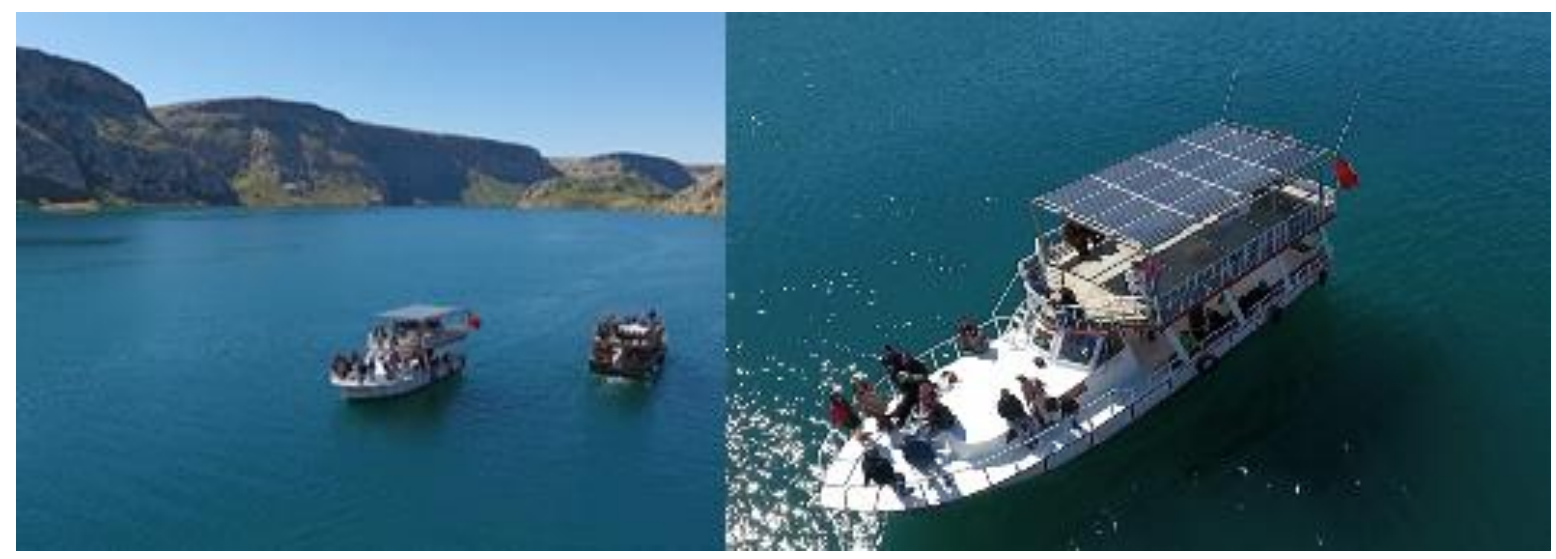

Şekil 3. Fırat Nehri üzerindeki tur tekneleri (solda) ve güneş enerjisi panelleri montajı yapılmış örnek tekne (sağda).

\subsection{Simülasyon sonuçları ve sistem analizi}

Mevcut teknolojiler dikkate alındığında, Rumkale-Halfeti bölgesinde güneş enerjili teknelerin yaygınlaştırılmasında hem maksimize edilmiş fotovoltaik alan ve hem de maksimize edilmiş akü kapasitesinin uzun yol güneş enerjili yolculuğun ana bileşenleri olduğu açıktır. Tekneye kurulan fotovoltaik sistem simülasyonu için, yaklaşık $25 \mathrm{~m}^{2}$ lik bir alana piyasada satılan güneş panellerinin kullanılacağı düşünülmüş ve fotovoltaik sistemin potansiyelinin hesaplanması için çatı üstü güneş enerjisi sistemi şeklinde hesaplamalar kullanılmıştır. Gaziantep’ten alınan iklim verilerini kullanarak PV*SOL'da simüle edilmiş ve elde edilen bölgeye özel enerji verim tahmini Tablo 1'de gösterilmiştir. 
Tablo 1. PV*SOL simülasyon programı ile bölgeye özel enerji verim tahmini.

\begin{tabular}{|c|c|c|}
\hline Ay & \multicolumn{2}{|c|}{ Bölgeye Özel Enerji Verimi } \\
\hline OCAK & $275 \mathrm{Ws} / \mathrm{m}^{2} / \mathrm{g}$ & $6,88 \mathrm{kWs} / \mathrm{g}$ \\
\hline ŞUBAT & $352 \mathrm{Wh} / \mathrm{m}^{2} / \mathrm{g}$ & $8,80 \mathrm{kWs} / \mathrm{g}$ \\
\hline MART & $543 \mathrm{Wh} / \mathrm{m}^{2} / \mathrm{g}$ & $13,56 \mathrm{kWs} / \mathrm{g}$ \\
\hline NİSAN & $687 \mathrm{Wh} / \mathrm{m}^{2} / \mathrm{g}$ & $17,18 \mathrm{kWs} / \mathrm{g}$ \\
\hline MAYIS & $766 \mathrm{Wh} / \mathrm{m}^{2} / \mathrm{g}$ & $19,15 \mathrm{kWs} / \mathrm{g}$ \\
\hline HAZŻRAN & $874 \mathrm{Wh} / \mathrm{m}^{2} / \mathrm{g}$ & $21,86 \mathrm{kWs} / \mathrm{g}$ \\
\hline TEMMUZ & $849 \mathrm{Wh} / \mathrm{m}^{2} / \mathrm{g}$ & $21,21 \mathrm{kWs} / \mathrm{g}$ \\
\hline AĞUSTOS & $761 \mathrm{Wh} / \mathrm{m}^{2} / \mathrm{g}$ & $19,02 \mathrm{kWs} / \mathrm{g}$ \\
\hline EYLÜL & $659 \mathrm{Wh} / \mathrm{m}^{2} / \mathrm{g}$ & $16,47 \mathrm{kWs} / \mathrm{g}$ \\
\hline EKİM & $486 \mathrm{Wh} / \mathrm{m}^{2} / \mathrm{g}$ & $12,15 \mathrm{kWs} / \mathrm{g}$ \\
\hline KASIM & $349 \mathrm{Wh} / \mathrm{m}^{2} / \mathrm{g}$ & $8,73 \mathrm{kWs} / \mathrm{g}$ \\
\hline ARALIK & $272 \mathrm{Wh} / \mathrm{m}^{2} / \mathrm{g}$ & $6,79 \mathrm{kWs} / \mathrm{g}$ \\
\hline
\end{tabular}

Sistem simülasyonu, fotovoltaik sistemden $200 \mathrm{kWs} / \mathrm{m}^{2} / \mathrm{y} 1 \mathrm{l} \mathrm{bir} \mathrm{verim} \mathrm{ve} 150 \mathrm{Wp} / \mathrm{m} 2$ pik kapasitesinin (bir modül yaklaşık $1,70 \mathrm{~m}^{2}$ ) beklenebileceğini göstermiştir. Ancak, yaz ayları boyunca günlük maksimum verim 3,5 kW pik kapasitesi ile günlük 21 kWs’i geçmeyecektir. Dolayısıyla, istenilen güneş enerjili teknenin tamamen elektrikli motorla çalıştırılması için yalnızca güneş enerjisi kullanıldığında hız çok düşük olacaktır. Bu da bölgedeki turist yoğunluğunun talebini karşılayamayacaktır. Tur teknesi sahiplerinin 40-50 dakikada tamamlamak istedikleri tur güzergâhında yaklaşı $15 \mathrm{~km} / \mathrm{s}$ hız ve $40 \mathrm{~kW}$ ’lık bir motor gücü gerekmektedir. Ancak tekne çatısına kurulacak olan PV sistemin üreteceği maksimum 21 kWs enerji bunu karşılayamayacaktır. Bu sebeple, akü sistemi teknenin iç hizmet tüketim kapasitesini karşılayabilecek şekilde boyutlandırılmıştır. Ancak ileriki dönemlerde, yeni bir tekne yapılırken eğer tekne tamamen elektrikli motorla çalıştırılacak şekilde tasarlanırsa, Şekil 4 istenen hızlara göre ve değişiklik gösteren tekne ağırlıkları için gerekli motor gücünü veya sabit hızda 1 saatlik sürüş için gerekli enerji talebini göstermektedir. Bu grafikte tekne ağırlığında \%1 bir azalma enerji talebinde ve motor gücünde \%0,44'lük bir azalmaya eşittir [29].

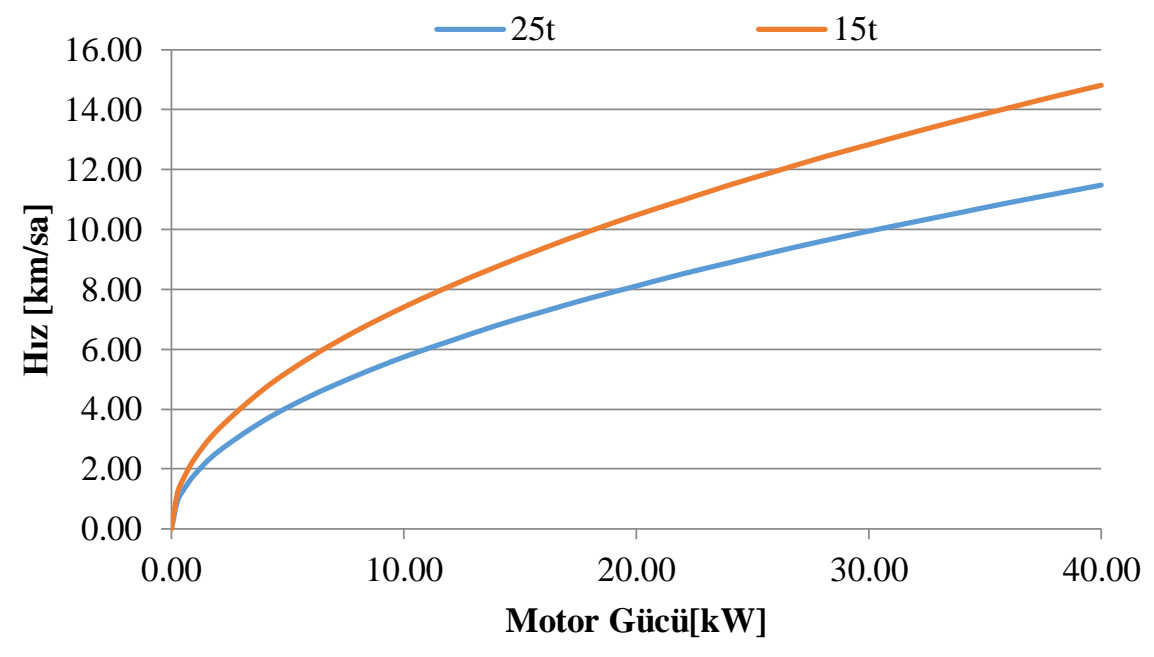

Şekil 4. Çeşitli hız seviyeleri ve ağırlıkları için motor güçleri arasındaki ilişki [29].

\subsection{Sistem performansı ve emisyon azaltımı}

Kurulan sistemin performansı öncelikle simülasyon sonuçlarına göre daha sonra ise 1 yıl boyunca işletilerek yakıt sarfiyatına göre hesaplanmıştır. Teknenin ürettiği enerjinin yakıt eşdeğeri ve işletme sırasındaki yakıt 
tüketimindeki değişiklik tespit edilerek IPCC'nin 2006 Kılavuzunda belirlediği kriterlerle emisyon azaltım hesaplamaları yapılmıştır:

1- Simülasyon sonuçlarına göre potansiyel enerji hesapları ve emisyon azaltımı hesaplaması:

$25 \mathrm{~m}^{2}$ için simülasyon sonuçlarına göre fotovoltaik sistem tekneye entegre edilmiş $24 \mathrm{~V}$ akü bataryasını şarj etmekte ve inverter ile elde edilen $220 \mathrm{~V}$ alternatif akımdan yıllık $5.540 \mathrm{kWs}$ sağlamaktadır. Enerji birimlerine göre dizel yakıtın \%35 verimle elektrik enerjisine dönüştürüldüğünü varsayarsak 1 litre dizel yakıt 3,5 kWs yapacaktır. Böylece $5.540 \mathrm{kWs}$ 'e karşılık gelen dizel miktarı yaklaşık 1583 lt olmaktadır. IPCC 2006 kılavuzuna göre yapılan hesaplamalarda dizel teknede 4,2506 $\mathrm{tCO}_{2} / \mathrm{y} 1 \mathrm{l}$ emisyonunu azaltılmaktadır. $\mathrm{Bu}$ sistem bölgedeki tüm tur teknelerine yani toplamda 40 tekneye uygulanırsa azaltım yaklaşık 170,0249 $\mathrm{tCO}_{2}$ /yıl olacaktır. Bölgedeki turizm sezonu yoğunluğu Haziran-Ağustos aylarındadır. Simülasyon sonuçlarına göre, turizm sezonu boyunca PV sistemi $74.508 \mathrm{kWs}$ enerji üretecektir. Tasarlanmış olan sistem bu ihtiyacı karşıladığında 40 tekne için 57,0895 $\mathrm{tCO}_{2} / \mathrm{y} ı 1$ emisyon azaltımı yapacaktır. (Tablo 2.)

Tablo 2. PV*SOL Simülasyon Verilerine Göre Emisyon Azaltım Miktarları.

\begin{tabular}{|c|c|c|c|c|c|}
\hline Tekne Sayısı & $\begin{array}{c}\text { Yıllık Üretilecek } \\
\text { Güneş Enerjisi } \\
\text { Eşdeğeri Dizel } \\
(\mathbf{k g})^{*}\end{array}$ & $\begin{array}{c}\mathrm{CO}_{2} \text { Emisyon } \\
\text { (ton)* }\end{array}$ & $\begin{array}{c}\text { Metan }(\mathrm{CH} 4) \\
\text { Emisyonu } \\
\mathrm{CO}_{2} \text { eşdeğeri } \\
\text { (t } \mathrm{CO}_{2} \mathrm{eq} / \mathrm{yl} \text { l)* }\end{array}$ & $\begin{array}{c}\text { Azot Dioksit } \\
\left(\mathrm{NO}_{2}\right) \mathrm{CO}_{2} \\
\text { eşdeğeri } \\
\left.\text { (t CO} \mathrm{CO}_{2} \mathrm{eq} / \mathrm{yl}\right)^{*}\end{array}$ & $\begin{array}{c}\text { Toplam } \\
\text { Emisyon } \\
\text { Azaltımı } \\
\left(\mathrm{CO}_{2} \text { ton } / \mathbf{y I}\right)^{*}\end{array}$ \\
\hline 1 & $1.313,77$ & 4,1860 & 0,0062 & 0,0583 & 4,2506 \\
\hline 40 & $52.550,8$ & 167,4427 & 0,2467 & 2,3353 & 170,0249 \\
\hline Turizm sezonu & $17.669,04$ & 56,2988 & 0,0054 & 0,7852 & 57,0895 \\
\hline
\end{tabular}

* IPCC 2006 kılavuzu Tablo 3.2.1 ve 3.2.2.'e göre; Enerji üretimi (43 TJ/Gt); Motorin yoğunluk (0,83 kg/lt); Üretilen Enerji Başına Metan Emisyonu (3,9 kg CH$/ \mathrm{TJ})$; Üretilen Enerji başına Karbon Emisyon (74100 kg CO $2 / \mathrm{TJ})$; Metanın $\mathrm{CO}_{2}$ eşdeğeri $\left(28 \mathrm{t} \mathrm{CO} 2\right.$ eq/t $\left.\mathrm{CH}_{4}\right)$; $\mathrm{NO}_{2}$ 'nun $\mathrm{CO}_{2}$ eşdeğeri $\left(265 \mathrm{t} \mathrm{CO}_{2} / \mathrm{NO}_{2}\right)$ olarak kabul edilmiştir.

2- 1 yıl boyunca işletme ve gerçekleşen dizel yakıt kullanımına göre karbon emisyonları hesaplanması:

Güneş enerjili sistem kurulmadan önce, tur tekneleri turistlerin çevreyi seyretme taleplerini karşılamak amacıyla bazı durumlarda demir atarak bekliyorlar ve bu bekleme sırasında iç hizmetleri karşılamak için tekneyi çalışır durumda tutuyorlardı. Bu işletme şartlarında tekneler sefer başına 18 lt yakıt harcamaktaydılar. Güneş enerjili sistem devreye alındıktan sonra tur tekneleri turistik talepleri karşılarken motor tamamen kapatılmış ve bu durumda sefer başına yaklaşık $3 \mathrm{lt}$ dizel motorin tasarrufu sağlanmıștır. Böylece, sefer başına yaklaşık \%16 tasarruf edilmiştir. 1 yıl boyunca ortalama 500 sefer yapan tekne yılda 1500 lt dizel motorin tasarrufu ve dolayısıyla da 4,0281 $\mathrm{tCO}_{2}$ karbon emisyonu azaltımı yapmıştır. Turizm sezonu düşünüldüğünde, teknelerin Pazar günleri için günde 5 sefer ve diğer günler ise \%30 yoğunlukla çalıştıkları varsayımıyla, sezonda 1 tekne 177 sefer ve 40 tekne 7080 sefer yapmaktadır. Böylece turizm sezonu boyunca tüm tekneler, sefer başına $3 \mathrm{lt}$, toplamda $21.240 \mathrm{lt}$. tasarruf yapacak ve 57,0382 $\mathrm{tCO}_{2}$ emisyon azaltımı sağlayacaklardır. Tablo 3 'te güneş enerjisi sistemi ile elde edilen yakıt tasarrufu ve emisyon azaltımları gösterilmektedir.

Tasarruf edilen yakıt göz önüne alındığında 1 tekne için 1500 lt. dizel yakıtın su kalitesini bozması önlenmiştir. Bölgedeki 40 teknenin tamamı güneş enerjili sisteme geçiş yaparsa 60.000 lt dizel yakıtın su kalitesini bozması önlenecektir. Ancak, gürültü kirliliğgi açısından değerlendirildiğinde mevcut sistem gürültü kirliliği açısından herhangi bir değişiklik oluşturmamıştır. Diğer taraftan, tekneler tamamen elektrikli olacak şekilde tasarlanırsa gürültü kirliliği ve tekne civarında bulunan 1200 ppm karbon monoksit tamamen ortadan kalkacaktır. Ayrıca, Birecik Baraj Gölü’nün içme suyu kaynağı olarak korunması ve sürdürülebilir turizm ile bölgenin istihdamının arttırılması da gerçekleştirilmiş olacaktır. 
Tablo 3. 1 yıl işletme sonucundaki Emisyon Azaltım Miktarları.

\begin{tabular}{|c|c|c|c|c|c|}
\hline Tekne Sayısı & $\begin{array}{c}\text { Yıllık Tasarruf } \\
\text { Edilen Dizel (kg)* }\end{array}$ & $\begin{array}{c}\mathrm{CO}_{2} \text { Emisyon } \\
\text { (ton)* }\end{array}$ & $\begin{array}{c}\text { Metan }(\mathrm{CH} 4) \\
\text { Emisyonu } \\
\mathrm{CO}_{2} \text { eşdeğeri } \\
\text { (t } \mathrm{CO}_{2} \mathrm{eq} / \mathrm{yl} \text { l)* } \\
\end{array}$ & $\begin{array}{c}\text { Azot Dioksit } \\
\left(\mathrm{NO}_{2}\right) \mathrm{CO}_{2} \\
\text { eşdeğeri } \\
\left.\text { (t CO} \mathrm{CO}_{2} \mathrm{eq} / \mathrm{yl}\right)^{*}\end{array}$ & $\begin{array}{c}\text { Toplam } \\
\text { Emisyon } \\
\text { Azaltımı } \\
\left(\mathrm{CO}_{2} \text { ton } / \mathrm{yl}\right)^{*}\end{array}$ \\
\hline 1 & 1245 & 3,9669 & 0,0058 & 0,0553 & 4,0281 \\
\hline 40 & 49800 & 158,6777 & 0,2338 & 2,2131 & 161,1247 \\
\hline Turizm sezonu & 21240 & 56,1719 & 0,0827 & 0,7834 & 57,0382 \\
\hline
\end{tabular}

* IPCC 2006 kılavuzu Tablo 3.2.1 ve 3.2.2.'e göre; Enerji üretimi (43 TJ/Gt); Motorin yoğunluk (0,83 kg/lt); Üretilen Enerji Başına Metan Emisyonu (3,9 kg CH$/ \mathrm{TJ}$ ); Üretilen Enerji başına Karbon Emisyon (74100 kg CO $2 / \mathrm{TJ}$ ); Metanın $\mathrm{CO}_{2}$ eşdeğeri $\left(28 \mathrm{t} \mathrm{CO}_{2}\right.$ eq/t $\left.\mathrm{CH}_{4}\right)$; $\mathrm{NO}_{2}$ 'nun $\mathrm{CO}_{2}$ eşdeğeri $\left(265 \mathrm{t} \mathrm{CO}_{2} / \mathrm{t} \mathrm{NO}_{2}\right)$ olarak kabul edilmiştir.

\section{Tartışma}

İklim değişikliği ile mücadelede yenilenebilir enerjilerin kullanımı önemli bir yer teşkil etmektedir. Düşük maliyetli yüksek kaliteli güneş enerjili tekneler yenilikçi kavramlar arasında gittikçe artan öneme sahip bir başlıktır. Artan enerji maliyetleri yerel tekne sahiplerini sürdürülebilirlik yönünde düşük maliyetli çözümler bulmaya zorlamaktadır. Rumkale ve Halfeti için günlük hayatta kullanılan ve geçim kaynağı olan tur teknelerinin güneş enerjisi ile çalıştırılması sürdürülebilir ulaşım ve turizm, hava ve su kirliliği, gürültü kirliliği gibi konuların çözümünü sağlayacaktır. Turistik teknelerde kullanılan bağımsız fotovoltaik paneller yenilikçi ve etkin bir çözüm olacaktır.

Bu çalışmadaki yaklaşımla, tur teknelerindeki iç hizmet tüketimleri hesaplanmış ve fotovoltaik sistemden üretilen enerji simüle edilerek enerji kazanımları belirlenmiştir. Bunun yanı sıra, güneş enerjili tekneler ve bunların fosil yakıt kullanan rakipleri ile aralarındaki enerji kazanımları ve çevresel etkileri hava, su ve gürültü kirliliği açılarından değerlendirilmiş ve elde edilen karbon emsiyon azaltımları simülasyon sonuçları ve 1 yıllık işletim sonuçlarına göre hesaplanmıştır. Bu hesaplamalara göre, bölgede çalışan teknelere güneş enerjisi sistemi kurulmasi durumunda;

Y1llık 1 tekne için 4,0281 ton ve 40 tekne için 161,1247 ton CO2 emisyon azaltımı,

Ylllkk 1 tekne için 1500 lt ve 40 tekne için 60.000 lt dizel yakıt tasarrufu,

Yıllık 1 tekne için 1500 lt ve 40 tekne için 60.000 lt yakıtın içme suyu kaynağının kalitesini bozmaması,

sağlanacaktır.

Gaziantep-Rumkale ve Halfeti'de uygulanan güneş enerjili tekne örneğinin sürdürülebilir ulaşım konusundaki pilot çalışmalara öncü olacağı düşünülmektedir. Bu örnek, hassas ekosistemlerdeki ulaşımın çevresel etkilerini azaltarak bölgelerin sürdürülebilirliğini artıracaktır. Bundan sonra yapılacak çalışmalarda, teknelerin tamamen elektrikli tekne olarak tasarlanması ve çalıştırılması için gerekli şartlar belirlenmelidir.

\section{Teşekkür}

Bu çalışmada, AB EuropAid TR2011/0135.15-01/30 sözleşme numaralı ve "AB'nin İklim Değişikliği Politikasının Türkiye'ye Tanıtılması Konusunda Sivil Diyalog" isimli projedeki simülasyon verileri kullanılmıştır. Projenin Lideri Gaziantep İTÜ Mezunları Derneği ve ortakları; Viyana Doğal Kaynaklar ve Yaşam Bilimleri Üniversitesi (BOKU), Gaziantep Hasan Kalyoncu Üniversitesi (HKÜ) ve tbw reseacrh GesmbH'dır.

\section{Kaynaklar}

[1] United Nations, Transforming Our World: The 2030 Agenda for Sustainable Development. Resolution of the General Assembly. 2015, 70/1 https://www.un.org/en/development/desa/population/migration/generalassembly/docs/globalcompact/A_RES_70_1_E.p df, Erişim tarihi 7 Nisan 2020.

[2] T.C. Orman ve Su işleri Bakanlığı; Göller ve Sulak Alanlar Eylem Planı 2018-2023, https://supolitikalaridernegiblog.files.wordpress.com/2018/02/gc3b6ller-ve-sulak-alanlar-eylem-plani.pdf, Erişim 17 Temmuz 2020.

[3] Byrnes T.A,. \& Warnken, J., Greenhouse gas emissions from marine tours: a case study of australian tour boat operators, Journal of Sustainable Tourism, 2006, 14 (3): 255-270, DOI: 10.1080/09669580608669058 
[4] Kokkranikal , J., McLellan, R., \& Baum, T., Island tourism and sustainability: a case study of the lakshadweep islands, Journal of Sustainable Tourism, 2003, 11(5): 426-447, DOI: 10.1080/09669580308667214.

[5] Veilleux, G., Potisat, T, Pezim, D., Ribback, C., Ling, J., Krysztofi'nski, A., Ahmed, A., Papenheim, J., vd., Technoeconomic analysis of microgrid projects for rural electrification: A systematic approach to the redesign of Koh Jik offgrid case study, Energy for Sustainable Development, 2020, 54: 1-13.

[6] Fulhu, M., Mohamed,M., ve Krumdieck, S., Voluntary demand participation (vdp) for security of essential energy activities in remote communities with case study in Maldives, Energy for Sustainable Development, 2019, 49: 27-38, https://doi.org/10.1016/j.esd.2019.01.002

[7] Djorup, S., ZinckThellufsen J., Sorknæs P., The electricity market in a renewable energy system, Energy, 2018, 162: 148-157, https://doi.org/10.1016/j.energy.2018.07.100

[8] Bulut, U, Muratoglu, G, Renewable energy in Turkey: great potential, low but increasing utilization, and an empirical analysis on renewable energy-growth nexus. Energy Policy, 2018, 123: 240-250.

[9] Zhao X., Ke Y., Zuo J., Xiong, W., Wu P., Evaluation of sustainable transport research in 2000-2019; Journal of Cleaner Production, 2020, 256: 120404.

[10] Mills E., Gengnagel T., Wollburg P., Solar-LED Alternatives to fuel-based lighting for night fishing; Energy for Sustainable Development, 2014, 21: 30-41

[11] Spyropoulos V.D., Mitronikas D. E, (2013). A review on the faults of electric machines used in electric ships. Advances in Power Electronics, 2013: 1-8, http://dx.doi.org/10.1155/2013/216870

[12] Aquawatt Tekne Özellikleri, http://www.aquawatt.at/GB/solarmobilitaet_18_GB.html), Erişim 15 Aralık 2017.

[13] Solar Water World Tekne Özellikleri, http://www.solarwaterworld.de/en/products/yacht/suncat-46.html), Erişim tarihi 15 Aralık 2017.

[14] Navalt Boats Tekne Özellikleri, http://www.navaltboats.com/navalt-products-solar-electric-ferry.php , Erişim tarihi 15 Aralık 2017

[15] European Comission, DG ENV, Environmental Impacts of Recreational Boating, News Alert Issue 87, 2007 https://ec.europa.eu/environment/integration/research/newsalert/pdf/87na2_en.pdf.

[16] Moreau, R., Nautical Activities: What Impact On The Environment? A Life Cycle Approach For "Clear Blue" Boating. Commissioned by the European Confederation of Nautical Industries - ECNI ; 2009, https://www.europeanboatingindustry.eu/images/Documents/For_publications/Nautical-activities_what-impact-on-theenvironment.pdf, Erişim tarihi 15 Kasım 2017

[17] İç Sularda Çalışan Gemi ve İç Su Araçları Yönetmeliği; Resmi Gazete Sayısı:27745, Tarih: 31.10.2010, https://www.mevzuat.gov.tr/mevzuat?MevzuatNo=14395\&MevzuatTur=7\&MevzuatTertip=5, Erişim Tarihi 10 Mayıs 2017.

[18] EU Directive 92/75/EEC; https://eur-lex.europa.eu/legal-content/EN/ALL/?uri=CELEX\%3A31992L0075, Erişim tarihi 7 Nisan 2017.

[19] T.C. Sağlık Bakanlı̆̆ı, Halk Sağlı̆̆ı Genel Müdürlüğü, Karbon Monoksit Zehirlenmesi, https://hsgm.saglik.gov.tr/tr/cevresagligi-ced/ced-birimi/karbonmonoksit-zehirlenmesi.html. Erişim tarihi 7 Nisan 2020.

[20] US Department of Health and Human Services; Carbon Monoxide emissions and exposure on recreational boats under Various Opertional Condition (2003), Report No: EPHB 171-31a; https://www.cdc.gov/niosh/surveyreports/pdfs/17131a.pdf?id=10.26613/NIOSHEPHB17131a, Erişim tarihi 7 Nisan 2020.

[21] Asplund T.R., The Effects of Motorized Watercraft on Aquatic Ecosystems; Wisconsin Department of Natural Resources, Bureau of Integrated Science Services and University of Wisconsin - Madison, Water Chemistry Program, PUBL-SS948-00, 2000; http://www.trpa.org/wp-content/uploads/2010-WI-Dept-of-Natural-Resources_UW-Boats-effects-onecosystems.pdf

[22] İMEAK (İstanbul, Marmara, Ege, Akdeniz ve Karadeniz) Deniz Ticaret Odası, Sürdürülebilir Denizcilik Uygulamaları Raporu, https://s3-eu-west-1.amazonaws.com/travelfoundation/wp-content/uploads/2017/12/05092443/SustainableBoating-Manual-Turkish.pdf,, 2017, Erişim tarihi 7 Nisan 2020.

[23] Erbe, C., Marley S.A., Schoeman, R.P., Smith, N.J., Trigg, L.E., Embling, B.C., The effects of ship noise on marine mammals - a review, Frontiers in Marine Science, 2019, https://doi.org/10.3389/fmars.2019.00606

[24] Ses seviyeleri; http://www.sesyalitimrehberi.com/teknik-bilgiler.htm, Erisim tarihi 7 Nisan 2017

[25] PV*SOL software; https://pvsol.software/en/features-pricing, Erişim tarihi 12 Nisan 2017

[26] Waldron, C.D., Maurice, L.Q, Kapshe, M., Allyn D.M., Locke, M., Pesmajoglou, S, IPCC Guidelines for National Greenhouse Gas $\quad$ Inventories; 2006, https://www.ipccnggip.iges.or.jp/public/2006gl/pdf/2/V2_3_Ch3_Mobile_Combustion.pdf, Erişi tarihi 13 Haziran 2020.

[27] Türkiye $\quad$ İstatistik $\quad$ Enstitüsü $\quad$ Nüfus $\quad$ Bilgileri; http://www.turkstat.gov.tr/Start.do;jsessionid=NgqDfTnTTDKY6Rg6XbhTBHNgfj8q8mc3Mppb0rLVTTK0QTv7nG4 x!-1904474571, Erișim tarihi 7 Nisan 2020.

[28] T.C. Enerji ve Tabi Kaynaklar Bakanlığı, Enerji Verimliliği ve Çevre Dairesi Başkanlığı, Türkiye Işınım Haritası, http://www.yegm.gov.tr/MyCalculator, Erişim tarihi 7 Nisan 2017.

[29] Boote Magazin, Motor gücü ve Hız Grafiği, https://www.boote-magazin.de/ratgeber/berechnungen.html. Erişim tarihi 7 Nisan 2017. 